\title{
Characterization of Droughts in Humid Subtropical Region, Upper Kafue River Basin (Southern Africa)
}

\author{
Muumbe K. Lweendo, Baohong Lu *, Meng Wang, Hanwen Zhang and Wei Xu \\ College of Hydrology and Water Resources, Hohai University, Nanjing 210098, China; \\ muumbek@yahoo.com (M.K.L.); hydrowang@163.com (M.W.); hanwenzhan05015134@163.com (H.Z.); \\ wei.xu.hhu@gmail.com (W.X.) \\ * Correspondence: lubaohong@126.com; Tel.: +86-25-8378-7311
}

Academic Editor: Athanasios Loukas

Received: 12 December 2016; Accepted: 26 March 2017; Published: 31 March 2017

\begin{abstract}
In this study, an integrated approach involving multiple standardized indicators and hydrological modeling (Soil and Water Assessment Tool, SWAT) was evaluated to reconstruct and characterize meteorological, agricultural and hydrological droughts in Upper Kafue River Basin of Zambia during 1984-2013. Standardized Precipitation Index (SPI) and Standardized Precipitation Evapotranspiration Index (SPEI) were used to identify meteorological droughts. Standardized Soil Moisture Index (SSI) was applied to characterize agricultural droughts and Standardized Runoff Index (SRI) was calculated to illustrate hydrological droughts. Input data for SRI and SSI computation was obtained from SWAT model which simulated daily and monthly runoff well with Nash-Sutcliffe efficiency (NSE) and coefficient of determination $\left(R^{2}\right)$ greater than 0.65 . The results showed that: (1) all indices were able to detect temporal variability of major drought events in a humid subtropical basin in Southern Africa; (2) SWAT successfully simulated runoff and soil moisture although soil moisture requires further calibration to increase accuracy; (3) the average duration and intensity for meteorological droughts at three-month time scale were lower but frequencies were higher compared to agricultural and hydrological droughts at 3- and 12-month aggregates; and (4) drought events exhibited a negative trend as evaluated by Mann-Kendall on SPEI, indicating an increase in drought severity, and correlation analysis between SPEI and SRI revealed that SPEI at 9-15 months has a strong link with hydrological conditions. This study showed that a comprehensive assessment of droughts by integrating multiple variables provided a versatile tool for drought monitoring and mitigation.
\end{abstract}

Keywords: drought indices and characterization; hydrological modeling; Soil and Water Assessment Tool; humid subtropical region

\section{Introduction}

Droughts are by far the costliest natural disaster and threat to water availability in the world [1]. In recent years, impacts of droughts have been experienced and monitored in many countries; they have led to devastating social, economic and environmental challenges such as increase in famines, energy crisis, reduced water supply and destruction of ecosystems [2]. Due to climate change, among many factors, it is projected that the intensity and recurrence of weather related disasters such as droughts will increase [3]. Further, population growth coupled with economic development has continued to put pressure on available water resources [4]. This prompts the need for prudent water resource strategies, which must incorporate drought management [5]. A good understanding of spatial and temporal characteristics of droughts at basin, regional and national level is required for efficient water resources management. Additionally, stringent quantitative assessment of droughts aid in reducing societal vulnerability by identifying triggers that apply for successful mitigation and preparedness [6,7]. 
Drought is a severe, recurring natural hazard that results in water deficit across the different components of the hydrologic cycle. It is a phenomenon that occurs in all climatic regions and presents unique challenges due to its distinctive attributes [8]. Four categories of droughts have been defined based on how the hydrological cycle is affected [9]: meteorological droughts, agricultural droughts, hydrological droughts and socio-economic droughts. Meteorological droughts occur when less than normal precipitation is received over a prolonged period, whereas agricultural droughts develop whenever there is insufficient soil moisture, thereby affecting forage and crop growth. Hydrological droughts eventuate when a region experiences below average surface and groundwater supplies over time; however, socio-economic droughts are triggered whenever there is failure of supply of goods and services that rely on water availability due to water deficit [9]. The first three drought definitions are based on a deficiency of different variables of the hydrological cycle and describe physical features of droughts. Even if all droughts originate from a precipitation deficiency, it is not enough to solely depend on this single variable to monitor and characterize drought events because other factors such as relative humidity, temperature and wind also play a vital role. It is therefore important to integrate precipitation and other climatic variables with water information, such as streamflow and soil moisture for effective monitoring of droughts $[5,9]$. Consequently, a comprehensive evaluation of droughts has to encompass meteorological, agricultural and hydrological droughts to have thorough understanding of a drought episode and how it impacts the various sectors [10]. However, one of the biggest challenges faced is having insufficient data, especially in data scarce regions. In order to overcome this shortcoming, the incorporation of hydrological models in drought studies has gained prominence [11,12].

Numerous indicators have been proposed to evaluate droughts such as the Standardized Precipitation Index (SPI) [13], Standardized Precipitation Evapotranspiration Index (SPEI) [14], Palmer Drought Severity Index (PDSI) [15], Soil Moisture Index (SMI) [16], Reconnaissance Drought Index (RDI) [17] and Standardized Runoff Index (SRI) [18]. Among these, PDSI and SPI are the most widely applied [17]. The complexity of calculation varies among indices, from single input variable for an index such as SPI to two or more variables for SPEI and PDSI, respectively. All these indices have their advantages and limitations but, when a combination of key indicators is applied for assessment, their combined strength compensates for limitations [8].

In this paper, the Upper Kafue River Basin (UKRB) in Zambia is taken as the study area due to its ecological, economical and geographic importance. Recent research has shown that occurrence of extreme weather events have been on the increase in the country [19]. UKRB is part of the Kafue River Basin (KRB), which is a sub-basin of the large Zambezi River Basin in Southern Africa [20]. KRB is the most industrialized region and about 50\% of Zambia's population live there [21]. It supports the majority of industrial, municipal water supply, agriculture and mining activities. Additionally, KRB is a vital habitat for a wide variety of animals and plants [20,22]. Therefore, there is great reliance on water resources, especially surface water but the threat of varying climatic conditions, more specifically droughts have made the region vulnerable to drought conditions and increased competition for the already scarce water resources [23].

Despite these challenges, the number of studies focusing on droughts in Zambia is limited with varying focus. Due to data scarcity, among other reasons [24], most studies are either at national or international scale. The known studies applied the theory of runs method to assess precipitation [25-28] and streamflow deficits (1906-1969) [29]. All the studies agree that droughts are becoming a recurrent feature, and that, to minimize impacts, pre-planned measures have to be taken. However, there is still no documented research done at regional scale, in particular, at basin level to investigate droughts, and lack of data is a possible hindrance to application of appropriate methods. This inadequacy in knowledge can be an obstacle in designing effective drought identification, monitoring and mitigation systems, which are a prerequisite for sustainable water resources usage and planning. Thus, need arises to study drought characteristics at a finer resolution and understand river basin dynamics during 
drought events. Moreover, at the time of this research, no known study was found to have investigated meteorological, agricultural and hydrological droughts simultaneously.

With this state of affairs, the present investigation attempts to: (1) understand characteristics of droughts in humid subtropical UKRB; (2) evaluate the capability of standardized drought indices representing different types of droughts in assessing drought variability during the period 1984-2013; (3) examine the applicability of Soil and Water Assessment Tool (SWAT) model for agricultural and hydrological drought studies in the basin; and (4) assess drought trends and explore the relationship between SPEI and SRI to understand the interaction between meteorological and hydrological droughts. It is expected that results from this study will be important in regional drought management and water resources planning, especially in data scarce regions.

\section{Materials and Methods}

\subsection{Study Area}

UKRB is located on the upper reaches of Kafue River and extends to the area before Itezhi-tezhi dam (Figure 1). It occupies an area of $104,514 \mathrm{~km}^{2}$ which represents about $67.4 \%$ of Kafue River Basin's total land area. UKRB is located between latitude $11^{\circ} 36^{\prime} \mathrm{S}$ and $15^{\circ} 47^{\prime} \mathrm{S}$ and between longitude $25^{\circ} 18^{\prime} \mathrm{E}$ and $28^{\circ} 55^{\prime} \mathrm{E}$. The Kafue River originates close to the border between Zambia and Congo in North-Western Province, and it flows southwards through dams at Itezhi-tezhi and Kafue gorge before joining the Zambezi River. Both dams are used for hydro-power generation [30,31]. Flow in UKRB is highly natural and unregulated hence a hydrological model can be applied for flow prediction with more accuracy. Elevation ranges from 1000 to $1570 \mathrm{~m}$ a.s.l., with higher elevation in the north descending southwards. There are four main types of vegetation: dense Miombo woodland, Mopani woodlands, Kalahari Chipya and dry evergreen Miombo, of which $80 \%$ of forest area is Miombo woodland which is dominated by Isoberlinia, Brachystegia and Julberna species. Land use and cover are influenced by impacts of the mining industry, its related industrial and urban activities. The land surface is characterized by a smooth plateau surface with subdued slopes, scattered inselbergs and shallow and wide drainage patterns [31]. The geotectonic profile of KRB comprises $65 \%$ crystalline and meta-sedimentary basement complex. Due to chemical weathering, Saprolite rock was produced whose thickness range from 25 to $60 \mathrm{~m}$. This rock formation has a great influence on the hydrology of the basin. The geologic formation of UKRB includes basement complex, muva-conglomerate, small areas of alluvium and Kalahari sands and Kundelungu limestone [31,32]. The main soils are loamy-sand and clay. Soils in most dambo areas are characterized by a dark color due to high organic content in the top $30 \mathrm{~cm}$ of the profile [33]. Top soil layers have high permeability and infiltration capacity, thus surface runoff is generally low, unless when a high intensity precipitation event occurs. However, the recharged top aquifer quickly feeds streamflow through baseflow and subsurface flow when soil moisture requirements are met. Zambia experiences humid subtropical climatic conditions, characterized by hot humid summers and mild to cool winters with moderate seasonality. Precipitation is influenced by the Inter Tropical Convergence Zone and El Niño Southern Oscillation. Mean annual precipitation and rainy days range from $657 \mathrm{~mm}$ and 68 days to $1402 \mathrm{~mm}$ and 142 days. Precipitation varies spatially and reduces from north to south, with high intra-seasonal variation. Two distinct seasons are experienced: the rainy season (November to April) and dry season, which is subdivided into dry-cold season (May to August) and dry-hot season (September to October) [31]. By taking the mean of regional monthly temperature and rainfall in the upper basin from 1984 to 2013 (Figure 2), the average annual temperature and rainfall are $20.9{ }^{\circ} \mathrm{C}$ and $1048.8 \mathrm{~mm}$, respectively. 


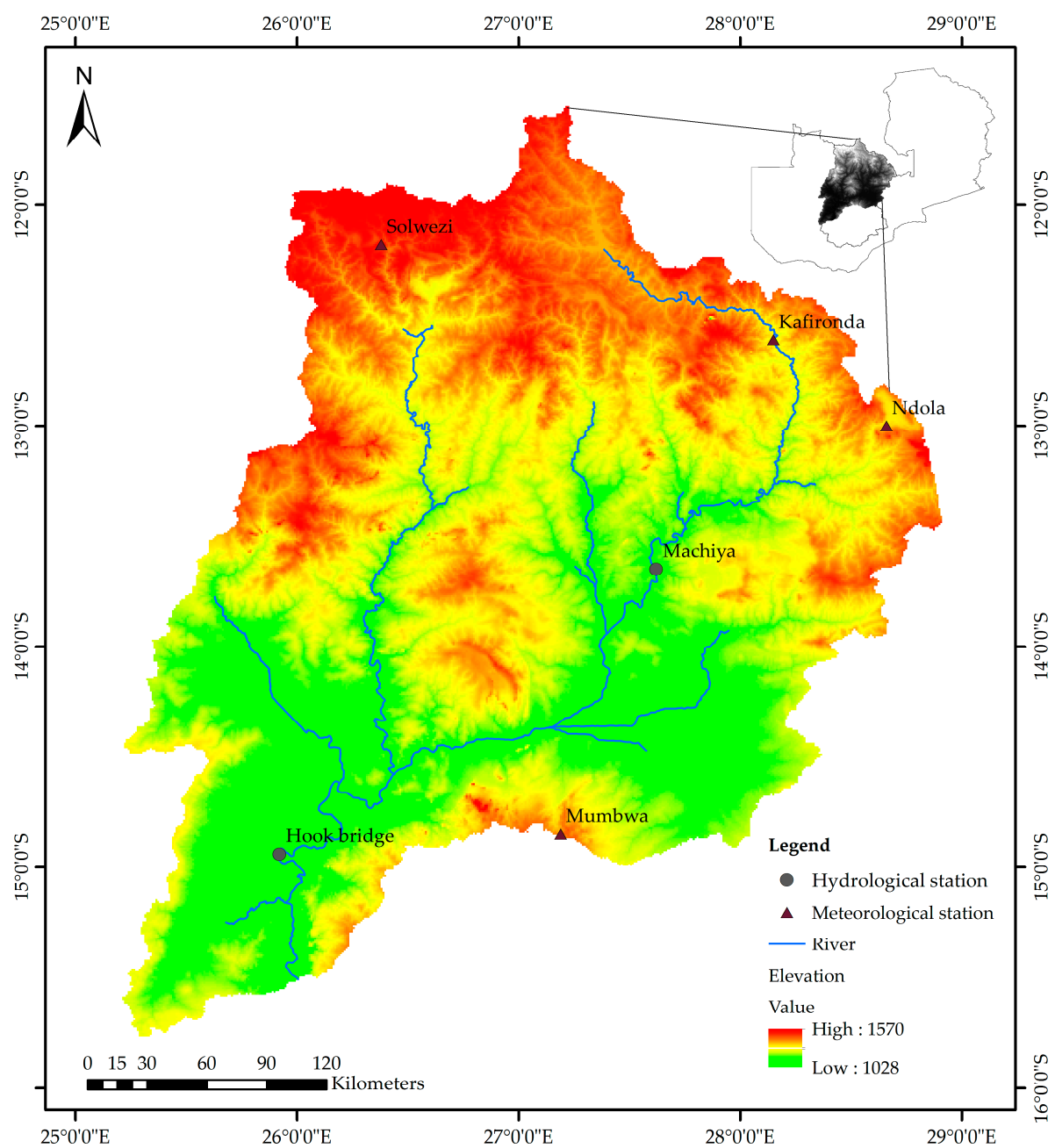

Figure 1. Study area, location and distribution of hydrological and meteorological stations.

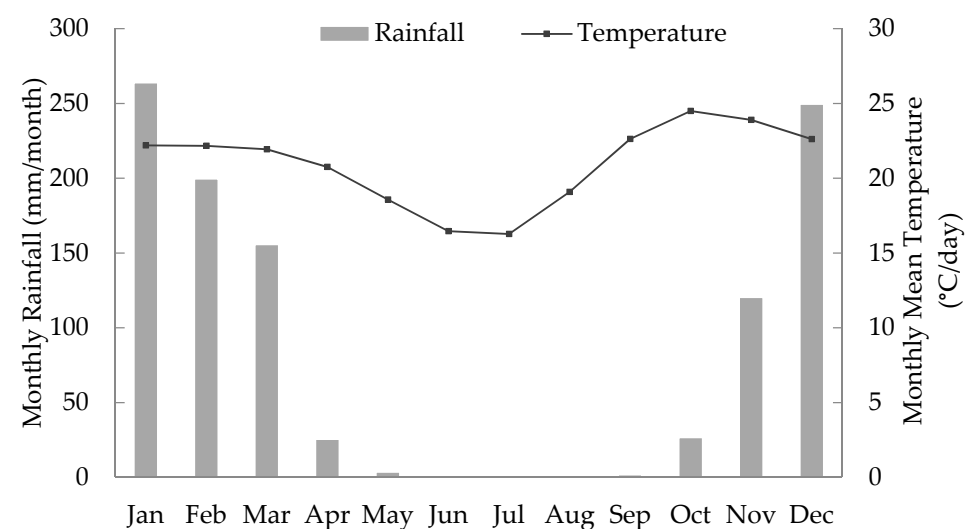

Figure 2. Regional mean monthly precipitation and temperature from 1984 to 2013.

\subsection{Sources of Data}

Observed monthly precipitation and temperature data from four meteorological stations were collected from the Meteorological Department of Zambia, which is under the Ministry of Transport, Works, Supply and Communications. The obtained data covered a period of 30 years from 1984 to 2013. Locations of these stations are shown in Figure 1 and Table 1. Station precipitation and temperature was then aggregated into regional time series using Thiessen polygon method [34]. Calculated regional 
precipitation and temperature time series were compared to each meteorological station using Pearson correlation $(R)$ to ensure that there was no inhomogeneity. Table 1 shows high correlation factors for all stations $(R \geq 0.91)$.

Table 1. Location of meteorological stations and Pearson correlation with regional data.

\begin{tabular}{ccccc}
\hline Station Name & Latitude $\left({ }^{\circ} \mathbf{S}\right)$ & Longitude $\left({ }^{\circ}\right.$ E) & Precipitation & Temperature \\
\hline Kafironda & -12.61 & 28.15 & 0.92 & 0.96 \\
Mumbwa & -15.08 & 27.19 & 0.92 & 0.99 \\
Ndola & -12.99 & 28.66 & 0.93 & 0.98 \\
Solwezi & -12.17 & 26.37 & 0.91 & 0.97 \\
\hline
\end{tabular}

The Digital Elevation Model (DEM) for SWAT model (Swat2012, USDA Agricultural Research Service, College Station, TX, USA) with a resolution of $90 \mathrm{~m}$ was downloaded from CGAIR Consortium for Spatial Information (http://srtm.csi.cgiar.org) [35]. The land use map was derived from USGS Land Cover Institute (LCI) on (http:/ /landcover.usgs.gov/). Furthermore, the spatial distribution of soils was obtained from the Digital Soil Map of the World on (http://www.fao.org/soils-portal/soilsurvey/soil-maps-and-databases/harmonized-world-soil-database-v12/en/) [36]. All maps were processed in ArcGIS (ArcGIS 10.1, ESRI, Redlands, CA, USA). Daily weather data for four stations corresponding with locations for meteorological stations in UKRB were obtained from the SWAT weather database (http://globalweather.tamu.edu/). Precipitation and temperature were corrected for upward biasness using a constant multiplication factor by comparing with observed records.

Observed discharge data of daily and monthly streamflow for two stations was collected from Department of Water Affairs (DWA), under Ministry of Mines, Energy and Water Resources. Machiya hydrological station has 14 years (1986-1999) of monthly time series data and Hook Bridge station, which is the key hydrological station on the downstream before Itezhi-tezhi dam has 20 years (1986-2005) of daily and monthly streamflow data.

\subsection{Methodology}

\subsubsection{Drought Indices}

Standardized drought indices were selected to evaluate different types of droughts. Meteorological droughts were evaluated based on SPI and SPEI. Agricultural droughts were assessed with Standardized Soil Moisture Index (SSI) and SRI was selected to monitor hydrological droughts. Indices were calculated at 3- and 12-month time-scales. Generally, standardized drought indices are computed at 1-, 3-, 6-, 9-, 12- and 24-month time scales but can be calculated on any aggregate depending on application [37]. Indices calculated at short time-scales (1, 3 and 6 months) explore short term seasonal approximation of precipitation and moisture conditions which have an effect on agriculture. Indices on longer time scales (9,12 and 24 months) are more indicative of hydrological conditions (runoff, reservoir levels and ground water) and social-economic effects [18,37-39]. In addition, for SRI, indices on short time scale are recommended for basins that have natural flow while longer aggregates (annual and interannual) are suitable for large basins with unnatural flow conditions due to artificial regulation.

The SPI was developed to define and characterize droughts at multiple timescales using precipitation as input data [13]. SPI is computed by fitting long term precipitation records to a gamma probability density function which is transformed to a normal distribution. The transformed probability gives the SPI values which mainly vary from -2 to 2 , although it is possible to get values that can be $>2$ or $<-2$. SPI calculation requires at least 20-30 years of monthly data; longer periods of input data give better results [40]. The World Meteorological Organization recommended the use of SPI as standard indicator to be used by all country Meteorological and Hydrological Services (NMHS) around the world to quantify meteorological droughts [37]. One of the advantages of SPI is that only 
one input variable (precipitation) is required for analysis, hence in data scarce regions, it is a reliable indicator to apply [37]. More details on calculation of SPI are provided in reference literature [13].

The concept used to compute SPI was extended to calculate SRI and SSI. Both indices use the procedure of fitting a probability distribution to data and transforming it to normal distribution. They are also quantified on multiple time scales similar to SPI. SRI was proposed to account for hydrological processes and conditions during drought episodes, SRI uses runoff time series as input data [18]. Input data for SRI and SSI computation was derived from the hydrological SWAT model.

SPEI is a multiscalar drought index based on precipitation and temperature. It adds the influence of potential evapotranspiration (PET) in a drought indicator [14]. SPEI considers cumulated anomalies of the climatic water balance. A simple status of the water balance is calculated as the difference between precipitation and potential evapotranspiration for the assessed month given by Equation (1).

$$
D_{J}=P_{j}-P E T_{j}
$$

Monthly PET is calculated by the Thornthwaite equation:

$$
P E T=16 K\left(\frac{10 T}{I}\right)^{m}
$$

where $P$ is monthly precipitation, $P E T$ is monthly potential evapotranspiration, $T$ is mean temperature and $I$ is the heat index calculated as the total of 12 monthly index values, $m$ is a coefficient that depends on heat index and $K$ is a factor of correction calculated as a function of the month and latitude.

The computation of SPEI is similar to SPI; the only difference is that it includes the influence of temperature to incorporate temperature changes on drought analysis. Due to limited observed data for this study, Thornthwaite equation was used to calculate PET since it only requires mean temperature and latitude to process. Detailed description of SPEI can be accessed in related literature [14].

Classification for all the above mentioned indices is as described for SPI [13]. This is outlined in Table 2.

Table 2. Classification of drought indices.

\begin{tabular}{cc}
\hline Drought Categories & SPI, SPEI, SSI, SRI Values \\
\hline Normal & $>-0.50$ \\
Mild drought & $(-1.00,-0.50]$ \\
Moderate drought & $(-1.50,-1.00]$ \\
Severe drought & $(-2.00,-1.5]$ \\
Extreme drought & $\leq-2.00$
\end{tabular}

Notes: SPI: Standardized Precipitation Index; SPEI: Standardized Precipitation Evapotranspiration Index; SSI: Standardized Soil Moisture Index; SRI: Standardized Runoff Index.

\subsubsection{Drought Evaluation}

Drought events for all indices are defined based on the work on SPI [13] since they all follow the same computation principals. A drought occurs when the SPI is continuously below zero and reaches a value of -1.0 or below and ends when SPI value becomes positive [13]. Whenever a drought event has been detected with a start and termination month, drought properties such as duration, intensity and frequency can be determined.

Drought variables are defined based on the concept of the run method [41]. The duration of a drought event equals the number of months between its start and end (not included). Severity is the absolute value of the sum of index values during a drought event and Intensity is obtained by dividing severity with duration while frequency of droughts refers to the number of drought events divided by total number of years of the study period. 


\subsubsection{Trend Analysis}

The non-parametric, rank based Mann-Kendall (MK) test is used to detect monotonic trends of SPEI and SRI indices. MK test determines if a series of observations of a random variable is generally increasing or decreasing with time at different levels of significance. Advantages of using MK test include: it is robust, requires data to be independent, and can accommodate outliers [42,43]. MK test statistic, $S$ and sign function are calculated by:

$$
S=\sum_{i=1}^{n-1} \sum_{j=i+1}^{n} \operatorname{sign}\left(x_{j}-x_{i}\right)
$$

where $n$ is the size of sample and $x$ is a data point

$$
\operatorname{sign}=\left\{\begin{array}{c}
+1 \quad \text { if }\left(x_{j}-x_{i}\right)>0 \\
0 \quad \text { if }\left(x_{j}-x_{i}\right)=0 \\
-1 \quad \text { if }\left(x_{j}-x_{i}\right)<1
\end{array}\right.
$$

The variance of $S$ is given by the equation:

$$
\sigma(S)=\sqrt{\frac{n(n-1)(2 n+5)}{18}}
$$

For $n>10$, the $Z$ statistic is computed by:

$$
Z=\left\{\begin{array}{l}
\frac{S-1}{\sqrt{\sigma(S)}} \text { if } S>0 \\
0 \text { if } S=0 \\
\frac{S+1}{\sqrt{\sigma(S)}} \text { if } S<0
\end{array}\right.
$$

The significance of the trend can be evaluated using the $Z$-value, where $Z$ is the standardized value of $Z$ statistic as suggested by [43]. A positive value of $Z$ signifies increasing trend while a negative value indicates decreasing pattern.

Mann-Kendall test requires serially independent data. If data are not serially independent, MK test has to be used in conjunction with pre-whitening to eliminate the influence of serial autocorrelation on the trend detection of data series [44-46]. In this study, we applied autocorrelation function (acf) and partial autocorrelation function (pacf) on SPEI and SRI series using R (R Project, University of Auckland, Auckland, New Zealand) to investigate presence of serial correlation. However, autocorrelation plots produced by R software implied that the autocorrelation present in the series was insignificant. Hence, data were used without any modifications.

\subsubsection{SWAT Model}

The semi-distributed SWAT model [47] was developed for UKRB after preparing all input maps (DEM, land use and soil), weather database and tables. The model begins by delineating the basin into watersheds based on topography then creates Hydrological Response Units (HRU). HRUs are areas with similar characteristics of land use, slope and soil type. The basin was divided into 23 sub-basins and 296 HRUs. The model ran at daily and monthly time steps for 30 years from 1984-2013. Two years were used for model warm-up from 1984 to 1985. Calibration was done at two hydrological stations, Hooks bridge and Machiya, for 10 years (1986-1995), and validation period was 10 years for Hooks bridge (1996-2005) and four years (1996-1999) for Machiya station. Model calibration and validation were carried out for each of the 23 subbasins and were performed with SWAT Calibration and Uncertainty Programs (SWAT-CUP) based on Sequential Uncertainty Fitting version 2 (SUFI-2) as optimizing algorithm [48]. The model performance was evaluated with Nash-Sutcliffe Efficiency $\left(E_{N S}\right)$ 
and coefficient of determination $\left(R^{2}\right)$, which are two of the most frequently used criteria in hydrologic studies [49]. The two indicators are expressed as:

$$
\begin{gathered}
E_{N S}=1-\frac{\sum_{i=1}^{n}\left(Q_{o b s}-Q_{s i m}\right)^{2}}{\sum_{i=1}^{n}\left(Q_{o b s}-\bar{Q}_{o b s}\right)^{2}} \\
R^{2}=\frac{\left[\sum_{i=1}^{n}\left(Q_{o b s}-\bar{Q}_{o b s}\right)\left(Q_{s i m}-\bar{Q}_{s i m}\right)\right]^{2}}{\sum_{i=1}^{n}\left(Q_{o b s}-\bar{Q}_{o b s}\right)^{2} \sum_{i=1}^{n}\left(Q_{s i m}-\bar{Q}_{s i m}\right)^{2}}
\end{gathered}
$$

where $Q_{o b s}$ is observed runoff, $Q_{s i m}$ is simulated runoff, $\bar{Q}_{o b s}$ is mean observed runoff, $\bar{Q}_{s i m}$ is simulated mean runoff and $n$ is the total number of entries. $E_{N S}$ evaluates how well observed and simulated data fit: a perfect fit has $E_{N S}=1 ; E_{N S}>0.75$ signifies very good performance of a model; and $E_{N S}>0.5$ means performance is acceptable or satisfactory. $R^{2}$ has a similar evaluation scale as $E_{N S}$ [50]. Due to lack of observed soil moisture data in the study area, simulated soil water content was evaluated by comparing the drought index with reported drought events in this region.

\section{Results}

\subsection{Applicability of SWAT Model}

SWAT model calibration and validation were based on daily and monthly runoff depth as shown in Table 3. At Hook Bridge, daily and monthly evaluation indicators $E_{N S}$ and $R^{2}$ were above 0.65 , reaching a maximum value of 0.78 . Monthly calibration and validation yielded better results compared to daily time step. Meanwhile, at Machiya station, monthly evaluation indicated performance ratios between 0.71 and 0.86 . The obtained indicators showed that performance of SWAT model in simulating runoff was reasonable. Figure 3 compares observed and modeled runoff depth at Hook Bridge. Monthly time series of river discharge and soil available water content were obtained from SWAT files for the period of 1986-2013, from which SSI and SRI were computed.

Table 3. Model performance ( $E_{N S}$ : Nash-Sutcliffe Efficiency and $R^{2}$ : Coefficient of determination).

\begin{tabular}{lcccccc}
\hline Simulation & \multicolumn{3}{c}{ Hook Bridge } & \multicolumn{2}{c}{ Machiya } \\
\hline & \multicolumn{2}{c}{ Daily } & \multicolumn{2}{c}{ Monthly } & \multicolumn{2}{c}{ Monthly } \\
\hline & $E_{N S}$ & $\boldsymbol{R}^{\mathbf{2}}$ & $\boldsymbol{E}_{N S}$ & $\boldsymbol{R}^{\mathbf{2}}$ & $\boldsymbol{E}_{N S}$ & $\boldsymbol{R}^{\mathbf{2}}$ \\
\hline Calibration & 0.70 & 0.70 & 0.75 & 0.75 & 0.71 & 0.71 \\
Validation & 0.66 & 0.67 & 0.77 & 0.78 & 0.86 & 0.86 \\
\hline
\end{tabular}

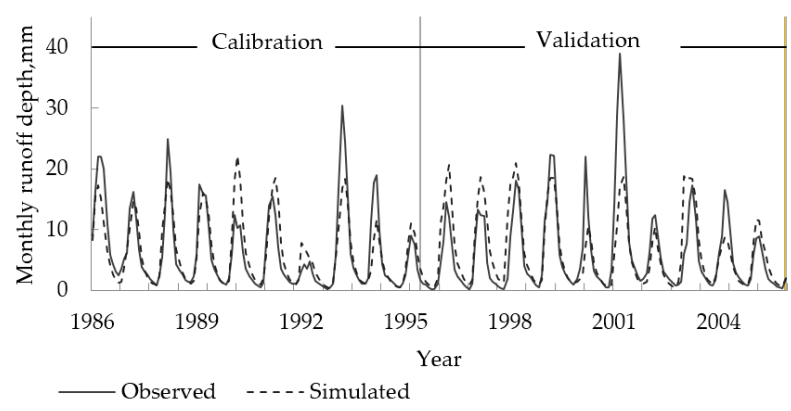

Figure 3. Observed and Simulated runoff during 1986-2005 for Hook Bridge hydrological station.

\subsection{Temporal Analysis of Droughts}

\subsubsection{Identification of Historical Droughts Based on Different Indices}

Temporal variations of drought indices are shown in Figure 4. It can be noted that all indices depict similar patterns but contrasts in severity and duration of drought episodes (Table 4). Common drought 
events are indicated during the years 1991/1992, 1994/1995, 1998/1999, 2002/2003, 2004/2005 and 2008/2009. SPI-3 detects three extreme droughts during 1991/1992, 1994/1995 and 2004/2005 seasons; severe droughts in 1990,1998/1999 and 2002/2003; and four moderate droughts in 1993, 2003/2004, 2008/2009 and 2013 as shown in Figure 4a. Meanwhile, SPI-12 in Figure 4b identifies three extreme droughts in 1991/1992, 1994/1995 and 2004/2005; and two moderate droughts (1987/1988, 2008/2009). In Figure 4c, SPEI-3 illustrates one extreme drought (2004/2005), five severe drought events (1990/1991, $1991 / 1992,1993-1996,1998 / 1999$, and 2001/2002) and three moderate droughts (2003/2004, 2008/2009 and 2013). SPEI-12 captured severe droughts in 1991/1992, 1994/1995 and 2002/2006 and one moderate drought (2008/2009). In Figure 4e, SSI-3 identifies three extreme droughts in 1991/1992, 1994/1994 and 2000-2003; one severe drought (1998); and four moderate events (1986/1987, 1988/1989, 1989/1990, and 2008), while Figure $4 \mathrm{f}$ highlights the three droughts identified by SSI-12. The hydrological index, SRI-3, depicted in Figure 4g identifies three extreme events in 1991/1992, 1999/2000 and 2001/2002; and two severe droughts in 1994/1995 and 2004/2005. On the other hand, SRI-12 in Figure 4h depicts one extreme event in 1992/1993, three severe events (1994/1995, 2000/2001, 2002/2003) and one moderate drought during 2004/2005.

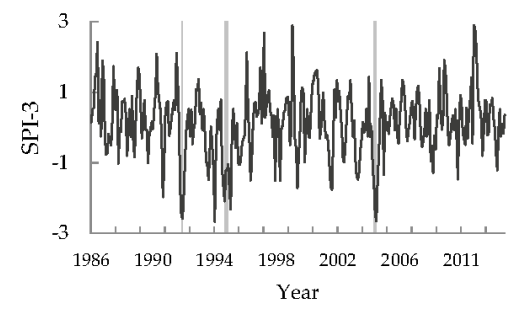

(a) Three-month SPI

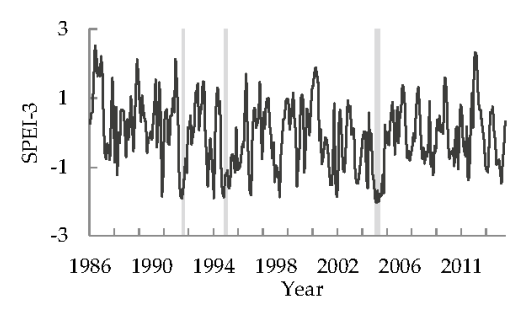

(c) Three-month SPEI

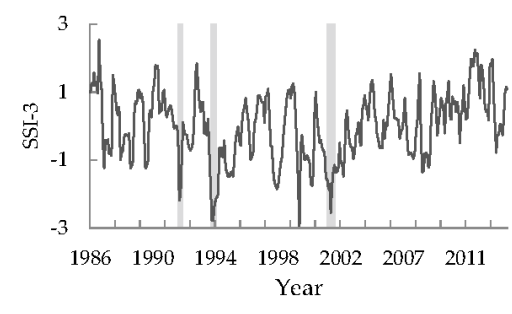

(e) Three-month SSI

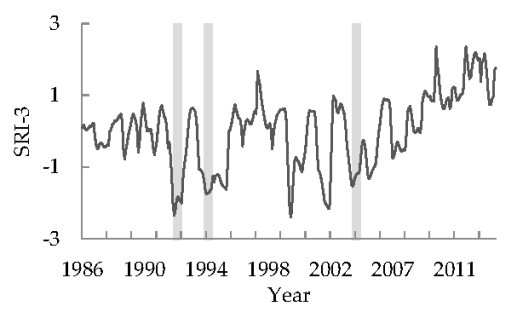

(g) Three-month SRI

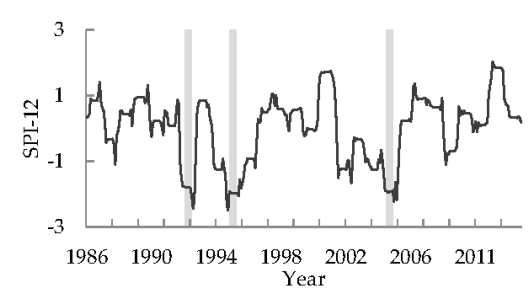

(b) Twelve-month SPI

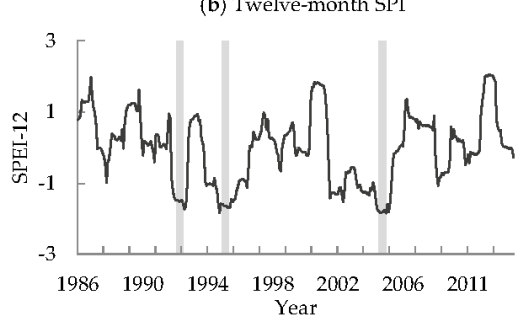

(d) Twelve-month SPEI

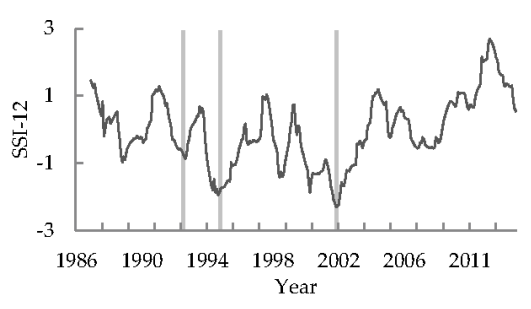

(f) Twelve-month SSI

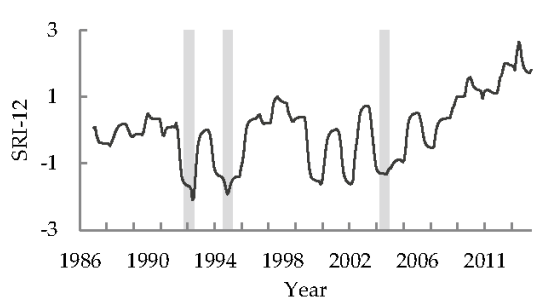

(h) Twelve-month SRI

Figure 4. (a-h) Temporal variation of droughts based on different indices at 3 and 12 month aggregates in UKRB. Grey lines show major drought events captured by the indices. 
Table 4. Categories of droughts captured by different indices.

\begin{tabular}{|c|c|c|c|c|c|c|c|c|}
\hline Categories & SPI-3 & SPI-12 & SPEI-3 & SPEI-12 & SSI-3 & SSI-12 & SRI-3 & SRI-12 \\
\hline Extreme drought & $\begin{array}{l}1991 / 1992 \\
1994 / 1995 \\
2004 / 2005\end{array}$ & $\begin{array}{l}1991 / 1992 \\
1994 / 1995 \\
2004 / 2005\end{array}$ & $2004 / 2005$ & None & $\begin{array}{l}1991 / 1992 \\
1994 / 1995 \\
2000-2003\end{array}$ & 2000-2004 & $\begin{array}{l}1991 / 1992 \\
1999 / 2000 \\
2001 / 2002\end{array}$ & $1992 / 1993$ \\
\hline Severe drought & $\begin{array}{c}1990,1998 / 1999 \\
2002 / 2003\end{array}$ & None & $\begin{array}{c}1990 / 1991 \\
1991 / 1992,1993-1996, \\
1998 / 1999,2001 / 02\end{array}$ & $\begin{array}{l}\text { 1991/1992, } \\
\text { 1994-1996, } \\
2002-2006\end{array}$ & 1998 & $1994 / 1995$ & $\begin{array}{l}\text { 1994/1995, } \\
2004 / 2005\end{array}$ & $\begin{array}{l}1994 / 1995 \\
2000 / 2001 \\
2002 / 2003\end{array}$ \\
\hline Moderate drought & $\begin{array}{c}1993 \\
2003 / 2004 \\
2008 / 2009 \\
2013\end{array}$ & $\begin{array}{l}1987 / 1988 \\
2008 / 2009\end{array}$ & $\begin{array}{c}2003 / 2004 \\
2008 / 2009,2013\end{array}$ & $2008 / 2009$ & $\begin{array}{l}1986 / 1987 \\
1988-1990 \\
2007 / 2008\end{array}$ & $1998 / 1999$ & None & $2004 / 2005$ \\
\hline Mild drought/Normal & Other seasons & Other seasons & Other seasons & Other seasons & Other seasons & Other seasons & Other seasons & Other seasons \\
\hline
\end{tabular}




\subsubsection{Evolution of Drought Indices for Major Droughts}

The evolution of three major droughts of 1991/1992, 1994/1995 and 2004/2005 (Figure 4) identified by indices applied in this study were investigated. The meteorological and agricultural indicators at three-month time scale were compared as shown in Figure 5a,c,e, while the hydrological drought index SRI, was compared with annual indicators SPI, SPEI and SSI as illustrated in Figure $5 b, d, f$. As shown in Figure 5a,b, all of the drought indices capture the evolution of the 1991/1992 drought. At three-month time scale, SPI and SPEI detect the initiation of this drought in January, before SSI identifies it in February as indicated in Figure 5a. Whereas SPI and SSI detect it as an extreme drought, SPEI capture it as a severe event. However, all indices indicate temporal variation during propagation of the drought. SSI is first to terminate in May but immediately after evolves into a mild drought. SPI and SPEI terminate almost at the same time, in July and August, respectively. While SPI ascends in a steady pattern, SPEI shows a drastic drop in index value then eventually terminates the drought. It can be noted that SPI exhibited the greatest response to drought conditions. SSI lagged in initiating the drought but terminated early. Evolution of SPI and SPEI were similar though severity shown by SPEI was larger. In Figure 5b, indices depicting hydrological drought conditions are all in phase. SPI- and SPEI-12 initiate and terminate almost at the same time. SRI-3 and -12 both exhibit a lagging tendency with initiation and termination of the drought: SRI-3 lagged by three months while SRI-12 delayed by five months. SSI is less sensitive and identifies a mild drought. Temporal variability of annual-scale indicators was less compared to three-month indices.

The 1994/1995 drought was equally as severe as the 1991/1992 event with a decrease in precipitation of $30.48 \%$ compared to the regional mean. In Figure 5c, SPI-3 and SPEI-3 could detect the onset and termination of this event. SSI-3 lags but identifies the drought though intensity is less compared to SPI-3 and SPEI-3. Twelve-month aggregate indicators in Figure 5d are all in phase; they initiate this drought in February 1994 and terminate it at the end of 1996 rainy season. All indices clearly identify the severity of this event, and they initiate and terminate at almost the same time.

During 2004/2005 drought, SPI-3 and SPEI-3 properly captured the beginning of the drought, SPI responds the most to show it as an extreme drought compared to SPEI, though SPI terminates it earlier than SPEI. SSI-3 identifies a mild drought. On the other hand, in Figure 5f, SRI shows a significant lag in reaction, and detects this drought as moderate. SSI fails to detect any abnormality. SPI and SPEI detect the 2004/2005 drought as extreme and severe events, respectively. Apart from SSI, all twelve-month indices have almost the same duration.

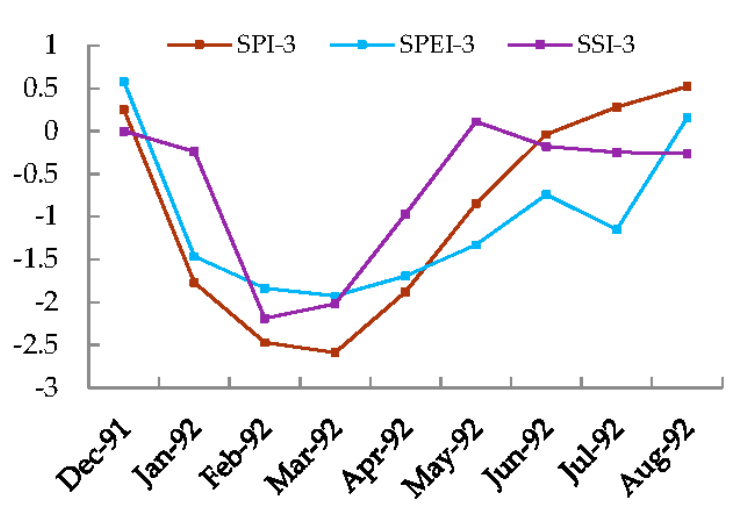

(a) $1991 / 1992$

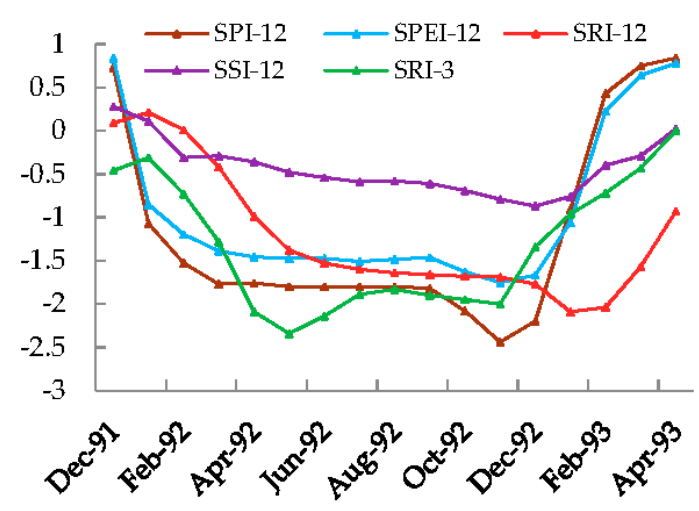

(b) $1991 / 1992$

Figure 5. Cont. 


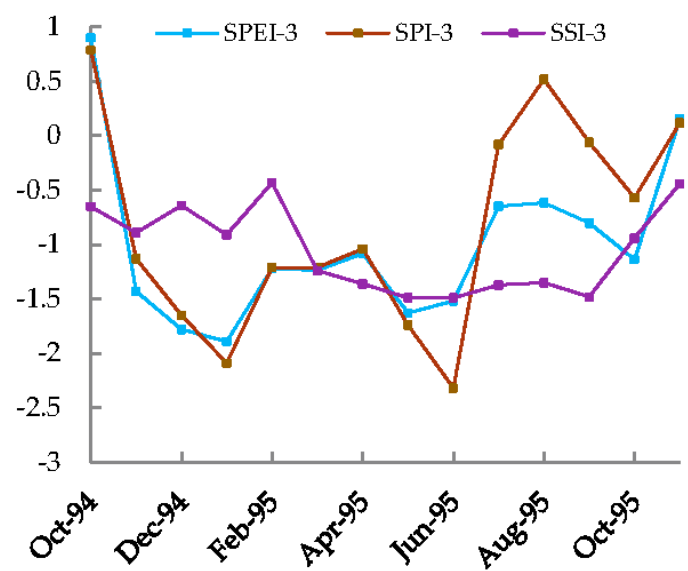

(c) $1994 / 1995$

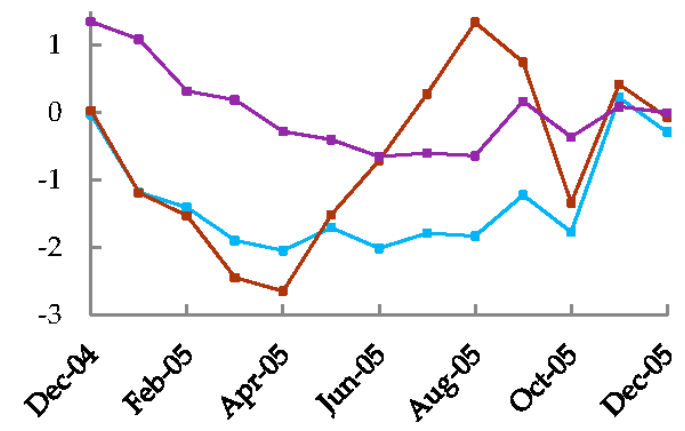

(e) $2004 / 2005$

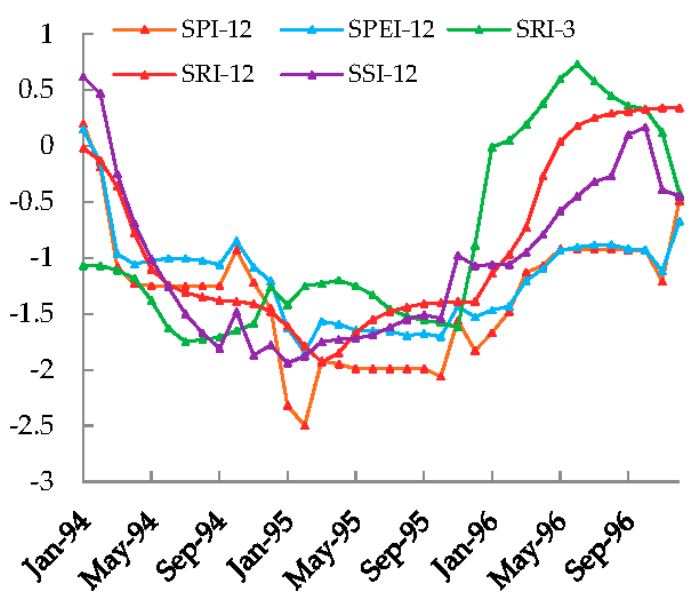

(d) $\quad 1994 / 1995$

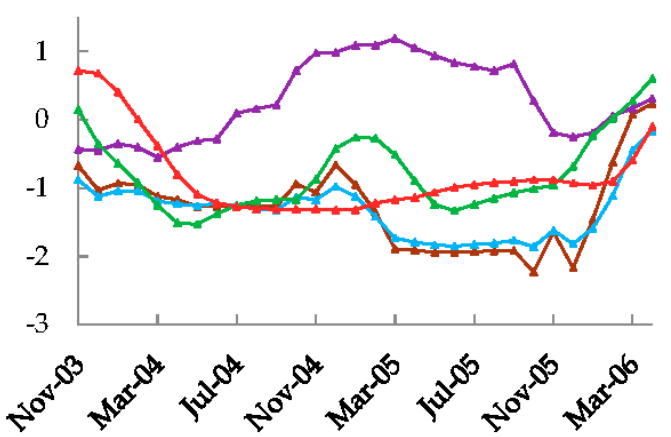

(f) $2004 / 2005$

Figure 5. Evolution of major droughts during 1991/1992, 1994/1995 and 2004/2005: $(\mathbf{a}, \mathbf{c}, \mathbf{d})$ meteorological and agricultural indices; and $(\mathbf{b}, \mathbf{d}, \mathbf{f})$ hydrological indices.

\subsection{Drought Duration, Intensity and Frequency}

Drought duration, intensity and frequency were analyzed (Table 5). At three-month time-scale, drought characteristics of SPEI are generally consistent with SPI results. The average drought duration for SPEI is eight months while SPI recorded five months. SRI and SSI have average duration of 19 and 13 months, respectively. Mean drought intensity for SPEI is 1.00, while SPI has 0.92 . SPI has a higher frequency of $60 \%$ followed by SPEI at $50 \%$. At twelve-month time scale, results for SPEI and SPI were quite consistent. Average duration for SPI, SPEI, SSI and SRI are 24, 29, 31 and 22 months, respectively. SPEI-12 has the longest duration of a drought event at 55 months while SSI- 12 has the lowest frequency of $10.0 \%$.

Table 5. Regional drought characteristics in Upper Kafue River Basin (UKRB) from 1984 to 2013.

\begin{tabular}{ccccccccc}
\hline Description & SPI-3 & SPEI-3 & SSI-3 & SRI-3 & SPI-12 & SPEI-12 & SSI-12 & SRI-12 \\
\hline Average drought duration (month) & 5 & 8 & 13 & 19 & 24 & 29 & 31 & 22 \\
Minimum duration (month) & 2 & 2 & 4 & 12 & 10 & 12 & 13 & 15 \\
Maximum duration (month) & 8 & 19 & 32 & 26 & 49 & 55 & 51 & 28 \\
Mean drought intensity & 0.92 & 1.00 & 1.02 & 1.26 & 1.07 & 1.11 & 1.11 & 1.07 \\
Drought Frequency (\%) & 60.0 & 50.0 & 30 & 16.67 & 16.7 & 13.3 & 10.0 & 16.67 \\
\hline
\end{tabular}




\subsection{Trend Analysis and Correlation between Meteorological and Hydrological Drought Indices}

Monotonic trends for SPEI and SRI were assessed at multiple time scales (Table 6). Positive values indicate an increasing tendency while negative values signify a decreasing trend. According to MK monthly analysis, SPEI-3 exhibited a significant decreasing tendency in June, September and October. The rest of the months were mostly negative but the change was insignificant. SPEI-12 also displayed a decreasing tendency but the change was insignificant. Conversely, SRI-3 and -12 exhibited increasing tendency, with SRI-12 having significant results from August to December. Annual analysis exhibited decreasing trend for SPEI at all time-scales while SRI showed an increasing trend. Seasonally, during the rainy season (November-April), SPEI showed decreasing tendency though not significant while SRI exhibited an increase with 95\% significance level. During the cool-dry season (May-August) and hot-dry (September-October), both SPEI and SRI showed significant decreasing and increasing tendency in results, respectively.

Table 6. Mann-Kendall (MK) test trend analysis calculated from SPEI/SRI at 3- and 12-month time scale.

\begin{tabular}{|c|c|c|c|c|c|c|c|c|}
\hline \multirow[t]{2}{*}{ Month } & \multicolumn{2}{|c|}{ SPEI-3 } & \multicolumn{2}{|c|}{ SPEI-12 } & \multicolumn{2}{|c|}{ SRI-3 } & \multicolumn{2}{|c|}{ SRI-12 } \\
\hline & $Z$ & $\mathbf{P}$ & $Z$ & $\mathbf{P}$ & $Z$ & $\mathbf{P}$ & $Z$ & $\mathbf{P}$ \\
\hline January & 1.22 & & -0.54 & & 1.71 & & 1.71 & \\
\hline February & -0.24 & & -0.66 & & 1.61 & & 1.47 & \\
\hline March & -0.50 & & -0.58 & & 1.57 & & 1.10 & \\
\hline April & -1.36 & & -0.66 & & 1.68 & & 1.47 & \\
\hline May & -0.82 & & -0.58 & & 1.63 & & 1.85 & \\
\hline June & -2.32 & * & -0.43 & & 1.41 & & 1.94 & \\
\hline July & -3.35 & & -0.58 & & 1.37 & & 1.94 & \\
\hline August & -3.43 & & -0.69 & & 1.54 & & 2.03 & * \\
\hline September & -1.96 & $*$ & -0.58 & & 1.72 & & 2.03 & * \\
\hline October & -2.82 & $* *$ & -0.51 & & 1.68 & & 2.06 & * \\
\hline November & 0.71 & & -0.39 & & 1.57 & & 2.13 & * \\
\hline December & 1.11 & & -0.36 & & 2.45 & $*$ & 2.09 & * \\
\hline Annual & -2.00 & * & -0.96 & & 2.12 & * & 1.41 & \\
\hline November-April & -0.07 & & -0.71 & & 2.16 & * & 1.76 & \\
\hline May-August & -2.98 & $* *$ & -0.62 & & 2.03 & * & 2.47 & * \\
\hline September-October & -2.95 & $* *$ & -0.66 & & 2.20 & $*$ & 2.47 & * \\
\hline
\end{tabular}

Notes: Z: test statistic, a positive (negative) value of $Z$ indicates an upward (downward) trend; ${ }^{*}$ and ${ }^{* *}$ means trends significant at $95 \%$ and $99 \%$ confidence level, respectively.

Figure 6 shows Pearson correlation coefficient $(R)$ between SRI and SPEI at multiple scales. Positive correlation values are obtained, an indication that increase in rainfall determines increase in runoff. The analysis reveals that high correlation coefficients are obtained when SPEI is between 8 and 18 months, with $R$ reaching peak value of 0.54 at SRI- 1 and -3 , and SPEI- 9 and -10 aggregates, respectively. It is also noted that SRI at shorter time scales (one and three months) reaches peak at lower SPEI values compared to SRI-12. SRI-12 exhibits the highest correlation at longer aggregates of meteorological drought indices. Temporal variability between SRI coefficients as SPEI time scale increased was also gradual as seen especially between SRI-1 and -3. 


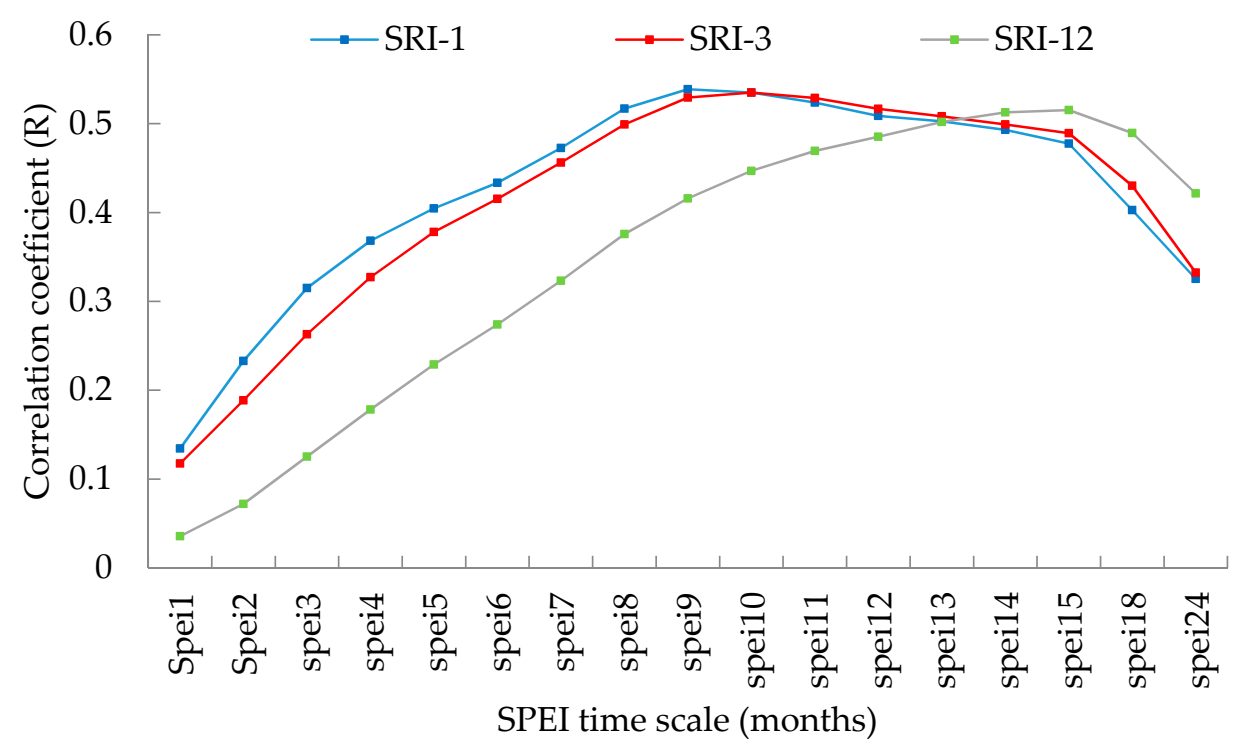

Figure 6. Correlation of SRI and SPEI at different timescales.

\section{Discussion}

To understand characteristics of droughts in UKRB, which is a data scarce region, an integrated approach involving observed data and SWAT hydrological modeling was applied to characterize droughts. This study investigated meteorological, agricultural and hydrological droughts simultaneously by applying well established standardized indices representing different components of the hydrological cycle for the period 1984-2013.

\subsection{Performance of Indices}

It was noted that all drought indices exhibited similar and consistent results, even if they were calculated from different input data. Although characteristics showed varying temporal properties, they identified important events that occurred during the study period. It has been reported that in the last 30 years, the study region experienced droughts in the seasons of 1991/1992, 1994/1995, $1997 / 1998,2000 / 2001,2002 / 2003,2004 / 2005$ and 2008/2009 [26,28,51-53]. It is also stated that drought episodes during 1991/1992, 1994/1995 and 2004/2005 were the most severe, with the 1991/1992 event being the most intense. All indices in this study except SSI-12 identified the major events, providing an indication that they can be applied for use. Analysis of the evolution of drought indices during typical droughts of 1991/1992, 1994/1995 and 2004/2005 showed that all indices captured the drought properties fairly well.

Further, SWAT model output based indices SSI and SRI captured most temporal characteristics of droughts, an indication that the model captured important hydrological processes in the basin. This was also validated by the evaluation indicators, $E_{N S}$ and $R^{2}$ (Table 3 ) which ranged from $0.66-0.86$ and were above the model performance benchmark of 0.5 [50]. The agricultural drought indicator SSI which is a proxy for simulated soil water content was compared to historical droughts to validate its usefulness. The performance of SSI was fair; it captured the major agricultural droughts which were also highlighted by [28], however, during the 2004/2005 drought, both SSI-3 and SSI-12 failed to express the severity. Considering lack of soil moisture data, the model calibration could not reach a higher level of accuracy. Compared to other indices, SRI and SSI had a lagging effect because the two indices are based on an interaction of more than one variable in the basin. SRI and SSI exhibit a slow response to precipitation because agricultural and hydrological droughts are not only linked to climatic variables (precipitation, temperature, etc.) but also heterogeneous geologic factors, soil type, topography, drainage area size, vegetation cover and human modifications in the catchment. 


\subsection{Characteristics of Droughts}

Analysis of drought characteristics revealed that with the exception of SRI-3, indices on three-month aggregate had low drought duration and intensity but high frequency compared to those on 12-month timescale. The basin experienced shorter but more frequent meteorological droughts compared to agricultural and hydrological droughts. A comparison of results between SPI-3 and SPEI-3 showed that SPEI captured the highest intensity (1.00) and average drought duration (eight months) but frequency increased when SPI was used (60\%). This suggests that drought episodes were influenced more by a combination of precipitation deficit and high temperature, which may have delayed moisture replenishment in the atmosphere thereby delaying streamflow and moisture storage based processes. Recent studies in this region have indicated that summer temperatures have been increasing at a high rate $\left(0.6{ }^{\circ} \mathrm{C} /\right.$ decade $)$ and precipitation decreasing due to climate change $[27,54,55]$. An increase in temperature may have triggered a rise in PET. A study on global warming observed that an increase in temperature results in an increased demand for PET leading to less precipitation and more drought conditions. This implies that results from SPEI are more consistent if climate change is taken into consideration [14].

The drought trend analysis results, though exhibiting mostly statistically insignificant results showed contrasting results for SPEI and SRI. Results from SPEI implied that the severity of droughts in UKRB has been on the increase while SRI suggests otherwise.

The relationship between meteorological and hydrological droughts was analyzed using SRI and SPEI at different aggregates. The response of runoff to SPEI was higher at longer timescales an indication that runoff generation is slow due to catchment characteristics such as geology, climate, basin size and land cover. The maximum correlation $(R=0.54)$ was obtained when SPEI was at nine- and ten-month aggregate, which coincides with the low flow season. A study exploring the connection between meteorological and hydrological droughts in a humid temperate region made similar observations, i.e., high correlations were found during low flow periods [56]. This result shows that streamflow is influenced more by precipitation of the previous months. Most studies that have assessed the relationship between meteorological and hydrological droughts have found the strongest linkage at SRI one-month timescale scale and SPI/SPEI 1-4 months [57-59] but, in our case, the highest correlation occurred for SPEI 8-15. This deviation could have arisen due to local characteristics of the basin and climatic zone hence causing a unique interaction between streamflow, precipitation and temperature. However, the result was consistent with a study in the Limpopo River Basin where higher correlation was obtained when SPEI time scale was 6-8 months [52].

\section{Conclusions}

In this study, characteristics of droughts were investigated using SPI, SPEI, SRI and SSI. The study concludes that, in UKRB, the average duration for meteorological droughts was 5-8 months, intensity was $\leq 1.00$ and frequencies were above $50.0 \%$ compared to agricultural and hydrological droughts (average duration: 13-31 months; intensity: $\geq 1.02$; and frequency: 10.0\%-16.67\%). All indices could identify the temporal variability of droughts but SPI and SPEI exhibited the best performance by capturing the evolution and severity of all reported droughts. SWAT successfully simulated runoff and soil moisture in the humid subtropical basin hence can be applied for research. Possible drought trends were evaluated using Mann-Kendall on SPEI and SRI. The indices depicted contrasting results but SPEI suggested that the period 1984-2013 had an increase in drought severity trends. Therefore, from a water resources management point of view, this would call for more preparedness and awareness to reduce vulnerability to future drought events. The correlation between SPEI and SRI revealed that SPEI at nine- and ten-month time scale has a strong link with SRI, hence can be used to monitor hydrological droughts when there is limited data.

Overall, the use of different indices representing different components of the hydrologic cycle integrates many factors that affect and trigger droughts, thus can aid in providing a wider understanding of characteristics of droughts on various water sectors, which a single index or method 
could fail to identify. The use of hydrological modeling in drought study also provides a powerful tool in data scarce regions. Findings of this research will be useful to water resources managers involved in drought planning and mitigation. Moreover, this study forms a basis for more informed application of standardized indices and sets a base to investigate the impacts of anthropogenic activities and climate change on streamflow, and how that affects industrial and municipal water supply, hydropower generation and agriculture activities downstream.

Acknowledgments: This work was supported by the Ministry of Water Resources' Special Funds for Scientific Research on Public Causes (201201026) and Innovation Project for Graduate Students in Jiangsu Province (KYZZ_0144). The authors would like to thank Meteorological Department as well as Department of Water Affairs (DWA) in Zambia for providing the meteorological and hydrological data respectively. We would also like to thank the three anonymous reviewers for their constructive comments and suggestions.

Author Contributions: Muumbe K. Lweendo and Baohong Lu designed the study. Muumbe K. Lweendo analyzed the data and wrote the manuscript. Baohong Lu supervised the work, discussed the results and revised the manuscript. Meng Wang participated in discussion of results and provided many improvements on the structure of the manuscript. Hanwen Zhang contributed to the discussion of the results. Wei Xu revised and edited the manuscript. All authors have read and approved the final manuscript.

Conflicts of Interest: The authors declare no conflict of interest.

\section{References}

1. Wilhite, D.A. Drought as a Natural Hazard: Concepts and Definitions. In Drought: A Global Assessment; Wilhite, D.A., Ed.; Routledge: London, UK, 2000.

2. United Nations Framework Convention on Climate Change (UNFCCC). Climate Change: Impacts, Vulnerabilities, and Adaptation in Developing Countries; United Nations Framework Convention on Climate Change: Bonn, Germany, 2007.

3. Solomon, S.; Qin, D.; Manning, M.; Chen, Z.; Marquis, M.; Averyt, K.B.; Tignor, M.; Miller, H.L. Climate Change 2007-The Physical Science Basis: Working Group I Contribution to the Fourth Assessment Report of the IPCC; Cambridge University Press: Cambridge, UK, 2007; Volume 4.

4. Guido, Z.; Hill, D.; Crimmins, M.; Ferguson, D. Informing Decisions with a Climate Synthesis Product: Implications for Regional Climate Services. Weather Clim. Soc. 2013, 5, 83-92. [CrossRef]

5. Wilhite, D. Drought Monitoring and Early Warning: Concepts, Progress and Future Challenges; World Meteorological Organization (WMO): Geneve, Switzerland, 2006.

6. Steinemann, A.C.; Cavalcanti, L.F. Developing Multiple Indicators and Triggers for Drought Plans. J. Water Resour. Plan. Manag. 2006, 132, 164-174. [CrossRef]

7. Wilhite, D.A.; Svoboda, M.D.; Hayes, M.J. Understanding the complex impacts of drought: A key to enhancing drought mitigation and preparedness. Water Resour. Manag. 2007, 21, 763-774. [CrossRef]

8. Heim, R.R., Jr. A review of twentieth-century drought indices used in the United States. Bull. Am. Meteorol. Soc. 2002, 83, 1149.

9. Wilhite, D.A.; Glantz, M.H. Understanding: The drought phenomenon: The role of definitions. Water Int. 1985, 10, 111-120. [CrossRef]

10. Vidal, J.; Martin, E.; Franchistéguy, L.; Habets, F.; Soubeyrux, J.M.; Balnchard, M.; Baillon, M. Multilevel and multiscale drought reanalysis over France with the Safran-Isba-Modcou hydrometeorological suite. Hydrol. Earth Syst. Sci. Discuss. 2010, 14, 459-478. [CrossRef]

11. Tong, R. Regional drought assessment using a distributed hydrological model coupled with Standardized Runoff Index. Proc. Int. Assoc. Hydrol. Sci. 2015, 368, 397-402.

12. Kamali, B.; Abbaspour, K.C.; Lehmann, A.; Wehrli, B.; Yang, H. Identification of spatiotemporal patterns of biophysical droughts in semi-arid region: A case study of the Karkheh river basin in Iran. Hydrol. Earth Syst. Sci. 2015, 12, 5187-5217. [CrossRef]

13. McKee, T.B.; Doesken, N.J.; Kleist, J. The relationship of drought frequency and duration to time scales. In Proceedings of the 8th Conference on Applied Climatology, 17-22 January 1993; American Meteorological Society: Boston, MA, USA, 1993.

14. Vicente-Serrano, S.M.; Beguería, S.; López-Moreno, J.I. A multiscalar drought index sensitive to global warming: The standardized precipitation evapotranspiration index. J. Clim. 2010, 23, 1696-1718. [CrossRef] 
15. Palmer, W.C. Meteorological Drought; US Department of Commerce, Weather Bureau: Washington, DC, USA, 1965; Volume 30.

16. Nam, W.-H.; Choi, J.Y.; Yoo, S.H.; Jang, M.W. A decision support system for agricultural drought management using risk assessment. Paddy Water Environ. 2012, 10, 197-207. [CrossRef]

17. Tsakiris, G.; Vangelis, H. Establishing a drought index incorporating evapotranspiration. Eur. Water 2005, 9, 3-11.

18. Shukla, S.; Wood, A.W. Use of a standardized runoff index for characterizing hydrologic drought. Geophys. Res. Lett. 2008, 35. [CrossRef]

19. Shitumbanuma, V. What has happened to Climate in Zambia in Recent Decades. In Proceedings of the 3rd SADC EU International Scientific Symposium-Towards Meeting the Challenges of Climate Change: Institutional Structure and Best Practices in Land and Water Management in Southern Africa, Lusaka, Zambia, 26 May 2008.

20. Howard, G.W.; Williams, G.J. Proceedings of the National Seminar on Environment and Change: The Consequences of Hydroelectric Power Development on the Utilization of the Kafue Flats, Lusaka, April 1978; Kafue Basin Research Committee of the University of Zambia: Lusaka, Zambia, 1982.

21. Schelle, P.; Pittock, J. Restoring the Kafue Flats: A partnership approach to environmental flows in Zambia. In Proceedings of the Eighth International River Symposium, Brisbane, Australia, 5-9 September 2005.

22. Burke, J.J. Approaches to integrated water resource development and management. Natl. Resour. Forum 1994. [CrossRef]

23. Fischer, G.; Shah, M.M.; van Velthuizen, H. Climate Change and Agricultural Vulnerability; IIASA Publications: Vienna, Austria, 2002.

24. Sivapalan, M. IAHS Decade on Predictions in Ungauged Basins (PUB) 2003-2012: PUB Science and Implementation Plan. Hydrol. Sci. J. 2003, 48, 857-880. [CrossRef]

25. Sichingabula, H.M. Rainfall variability, drought and implications of its impacts on Zambia, 1886-1996. IAHS Publ. 1998, 252, 125-134.

26. Muchinda, M. Drought Incidence in Zambia over the Thirty-Year Period 1979/71-1999/2000. In Proceedings of the Second International Conference on Tropical Climatology, Meteorology and Hydrology, Brussels, Belgium, 13-14 December 2001; Royal Meteorological Institue of Belgium: Brussels, Belgium, 2004.

27. Jain, S. An Empirical Economic Assessment of Impacts of Climate Change on Agriculture in Zambia; World Bank Policy Research Working Paper, No. 4291; World Bank: Washington, DC, USA, 2007.

28. Lekprichakul, T. Impact of 2004. 2005 Drought on Zambia's Agricultural Production and Economy: Preliminary Results (Working Paper on Social-Ecological Resilience Series No. 2008-002); Research Institute for Humanity and Nature: Kyoto, Japan, 2008.

29. Sichingabula, H.M.; Sikazwe, H. Occurrence, seventy and magnitude of hydrological drought in Zambia: Impacts and implications. Hydrol. Extremes Underst. Predict. Mitigating 1999, 255, 297-305.

30. Obrdlik, P.; Mumeka, A.; Kasonde, J. Regulated rivers in Zambia-The case study of the Kafue river. Regul. Rivers Res. Manag. 1989, 3, 371-380. [CrossRef]

31. Mwelwa, E.M. The Application of the Monthly Time Step Pitman Rainfall-Runoff Model to the Kafue River Basin of Zambia; Rhodes University: Grahamstown, South Africa, 2004.

32. Mambwe, S.H.; Sikatali, C. Mineralisation and Potential of the Gemstone Industry of Zambia; British Geological Survey: Keyworth, UK, 1994.

33. Aregheore, E.M. Country Pasture/Forage Resource Profiles: Zambia; FAO: Rome, Italy, 2009.

34. Sheriza, M.; Ainuddin, N.A.; Hazandy, A.H.; Zulhaidi, M.S.H. Annual rainfall estimation based on two different methods. J. Environ. Hydrol. 2011, 19, 1-9.

35. Jarvis, A.; Reuter, H.I.; Nelson, A.; Guevara, E. Hole-Filled SRTM for the Globe Version 4. CGIAR-CSI SRTM 90 m Database 2008. Available online: http:/ / srtm.csi.cgiar.org (accessed on 25 March 2017).

36. Sanchez, P.A.; Ahamed, S.; Carré, F.; Hartemink, A.E.; Hempel, J.; Huising, J.; Lagacherie, P.; McBratney, A.B.; McKenzie, N.J.; de Lourdes, M.; et al. Digital soil map of the world. Science 2009, 325, 680-681. [CrossRef] [PubMed]

37. Svoboda, M.; Hayes, M.; Wood, D. Standardized Precipitation Index User Guide; World Meteorological Organization: Geneva, Switzerland, 2012.

38. Hayes, M.J.; Svoboda, M.D.; Wilhite, D.A.; Vanyarkho, O.V. Monitoring the 1996 drought using the standardized precipitation index. Bull. Am. Meteorol. Soc. 1999, 80, 429. [CrossRef] 
39. Potop, V.; Boroneanţ, C.; Možný, M.; Štěpánek, P.; Skalák, P. Observed spatiotemporal characteristics of drought on various time scales over the Czech Republic. Theor. Appl. Climatol. 2014, 115, 563-581. [CrossRef]

40. Guttman, N.B. On the sensitivity of sample L moments to sample size. J. Clim. 1994, 7, 1026-1029. [CrossRef]

41. Yevjevich, V.M. An Objective Approach to Definitions and Investigations of Continental Hydrologic Droughts; Hydrology Papers (Colorado State University), No. 23; Colorado State University: Fort Collins, CO, USA, 1967.

42. Helsel, D.R.; Hirsch, R.M. Statistical Methods in Water Resources; Elsevier: Amsterdam, The Netherlands, 1992; Volume 49.

43. Yue, S.; Pilon, P.; Cavadias, G. Power of the Mann-Kendall and Spearman's rho tests for detecting monotonic trends in hydrological series. J. Hydrol. 2002, 259, 254-271. [CrossRef]

44. Yue, S.; Wang, C.Y. Applicability of prewhitening to eliminate the influence of serial correlation on the Mann-Kendall test. Water Resour. Res. 2002, 38. [CrossRef]

45. Bayazit, M.; Önöz, B. To prewhiten or not to prewhiten in trend analysis? Hydrol. Sci. J. 2007, 52, 611-624. [CrossRef]

46. Von Storch, H. Misuses of statistical analysis in climate research. In Analysis of Climate Variability; Springer: Berlin/Heidelberg, Germany, 1999; pp. 11-26.

47. Arnold, J.G.; Srinivasan, R.; Muttiah, R.S.; Williams, J.R. Large area hydrologic modeling and assessment part I: Model development. J. Am. Water Resour. Assoc. 1998, 34, 73-89. [CrossRef]

48. Abbaspour, K.; Vejdani, M.; Haghighat, S. SWAT-CUP Calibration and Uncertainty Programs for SWAT. MODSIM 2007 International Congress on Modelling and Simulation, Modelling and Simulation Society of Australia and New Zealand. 2007. Available online: https:/ / www.researchgate.net/publication/266215018_ SWAT-CUP_calibration_and_uncertainty_programs_for_SWAT (accessed on 30 March 2017).

49. Krause, P.; Boyle, D.; Bäse, F. Comparison of different efficiency criteria for hydrological model assessment. Adv. Geosci. 2005, 5, 89-97. [CrossRef]

50. Moriasi, D.N.; Arnold, J.G.; Van Liew, M.W.; Bingner, R.L.; Harmel, R.D.; Veith, T.L. Model evaluation guidelines for systematic quantification of accuracy in watershed simulations. Trans. ASABE 2007, 50, 885-900. [CrossRef]

51. Thurlow, J.; Zhu, T.; Diao, X. The Impact of Climate Variability and Change on Economic Growth and Poverty in Zambia; IFPRI Discussion Paper 00890; IFPRI: Washington, DC, USA, 2009.

52. Trambauer, P.; Maskey, S.; Werner, M.; Pappenberger, F.; Van Beek, L.P.H.; Uhlenbrook, S. Identification and simulation of space-time variability of past hydrological drought events in the Limpopo River basin, southern Africa. Hydrol. Earth Syst. Sci. 2014, 18, 2925-2942. [CrossRef]

53. Vogel, C.; Koch, I.; van Zyl, K. “A Persistent Truth"-Reflections on Drought Risk Management in Southern Africa. Weather Clim. Soc. 2010, 2, 9-22. [CrossRef]

54. Hulme, M. Climate Change and Southern Africa: An Exploration of Some Potential Impacts and Implications for the SADC Region; Climatic Research Unit, University of East Anglia: Norwich, UK, 1996.

55. Gannon, C.; Kandy, D.; Turner, J.; Kumar, I.; Pilli-Sihvola, K.; Chanda, F.S. Nearterm Climate Change in Zambia; Red Cross/Red Crescent Climate Centre: The Hague, The Netherlands, 2014.

56. Haslinger, K.; Koffler, D.; Schöner, W.; Laaha, G. Exploring the link between meteorological drought and streamflow: Effects of climate-catchment interaction. Water Resour. Res. 2014, 50, 2468-2487. [CrossRef]

57. Vicente-Serrano, S.M.; López-Moreno, J.I. Hydrological response to different time scales of climatological drought: An evaluation of the Standardized Precipitation Index in a mountainous Mediterranean basin. Hydrol. Earth Syst. Sci. 2005, 9, 523-533. [CrossRef]

58. Zhao, L.; Wu, J.; Fang, J. Robust Response of Streamflow Drought to Different Timescales of Meteorological Drought in Xiangjiang River Basin of China. Adv. Meteorol. 2016, 2016, 1634787. [CrossRef]

59. Xuchun, Y.; Li, X.; Xu, C.Y.; Zhang, Q. Similarity, difference and correlation of meteorological and hydrological drought indices in a humid climate region-the Poyang Lake catchment in China. Hydrol. Res. 2016, 47, 1211-1223.

(C) 2017 by the authors. Licensee MDPI, Basel, Switzerland. This article is an open access article distributed under the terms and conditions of the Creative Commons Attribution (CC BY) license (http:/ / creativecommons.org/licenses/by/4.0/). 